\title{
COVID-19 in perinatal period: questions and consequences
}

\author{
Duygu Tunçel ${ }^{\ominus}$, Leyla Karadeniz Bilgin ${ }^{\oplus}$, Zeynep İnce ${ }^{\oplus}$, Asuman Çoban ${ }^{\odot}$ \\ Department of Neonatology, İstanbul University Faculty of Medicine, İstanbul, Turkey.
}

\begin{abstract}
Background. The effect of COVID-19 infection on newborn babies is not yet clear. Babies born to pregnant women with suspected or proven COVID-19 or babies who had contact with infected people are considered to be at risk. In this review, intrauterine problems that may be caused by COVID-19 infection, delivery room approach, postnatal follow-up, precautions and controversies regarding breastfeeding and vaccination are discussed.

Methods. The articles published between March 2020 and June 2021 were searched in Pubmed, Cochrane Library and Google Scholar databases using the keywords COVID-19 and newborn, perinatal period, vertical transmission, pregnancy, breast milk and vaccines. The updated information and recommendations are presented.

Conclusions. Our knowledge of the perinatal and neonatal effects of COVID-19 infection changes rapidly. Therefore, close follow-up of the mother-infant dyads is important. Larger epidemiological and clinical cohort studies are needed to better understand the possible implications and long-term outcomes of COVID-19 infection and also maternal vaccination in newborn infants.
\end{abstract}

Key words: COVID-19, newborn, pandemic, vertical transmission, breastfeeding.

In November 2019, severe cases of pneumonia started to increase in Wuhan, China, and an agent could not be isolated in the beginning. As of February 7, 2020, it was determined that this virus, which causes fever, cough and intense inflammation in the lungs, is a virus from the Coronaviridae family and named SARS-CoV-2 due to its similar genetic structure with SARS coronavirus. ${ }^{1,2}$ The high contagiousness has caused the virus to spread rapidly to different geographical regions of the world and on March 112020 the World Health Organization (WHO) declared a pandemic due to COVID-19 infection (Coronavirus Infectious Disease 2019). ${ }^{3}$

Although we still do not have enough information about the spread, course, diagnosis, treatment and prevention of this viral disease, according to the early period data published by

\footnotetext{
$凶$ Duygu Tunçel

tncldyg@yahoo.com
}

Received 17th March 2021, revised 23rd June 2021, 1st October 2021, accepted 7th October 2021.
China, it was stated that the disease was not fatal in children. Mortality and morbidity compared to adults are still lower in the pediatric age group, especially under 1 year of age. However, we now know that the children can be seriously affected by COVID-19., ${ }^{4,5}$

Our knowledge on the care and treatment of newborn babies in the prenatal, natal and postnatal periods is updated in the later stages of the pandemic. In this article, current recommendations are made regarding the treatment and management of newborns in the perinatal period (Fig. 1).

\section{Method}

The articles published in English and Turkish between March 2020 and June 2021 were searched in Pubmed, Cochrane Library and Google Scholar databases using the keywords COVID-19 and newborn, perinatal period, vertical transmission, pregnancy, breastfeeding and vaccines. The updated information and 


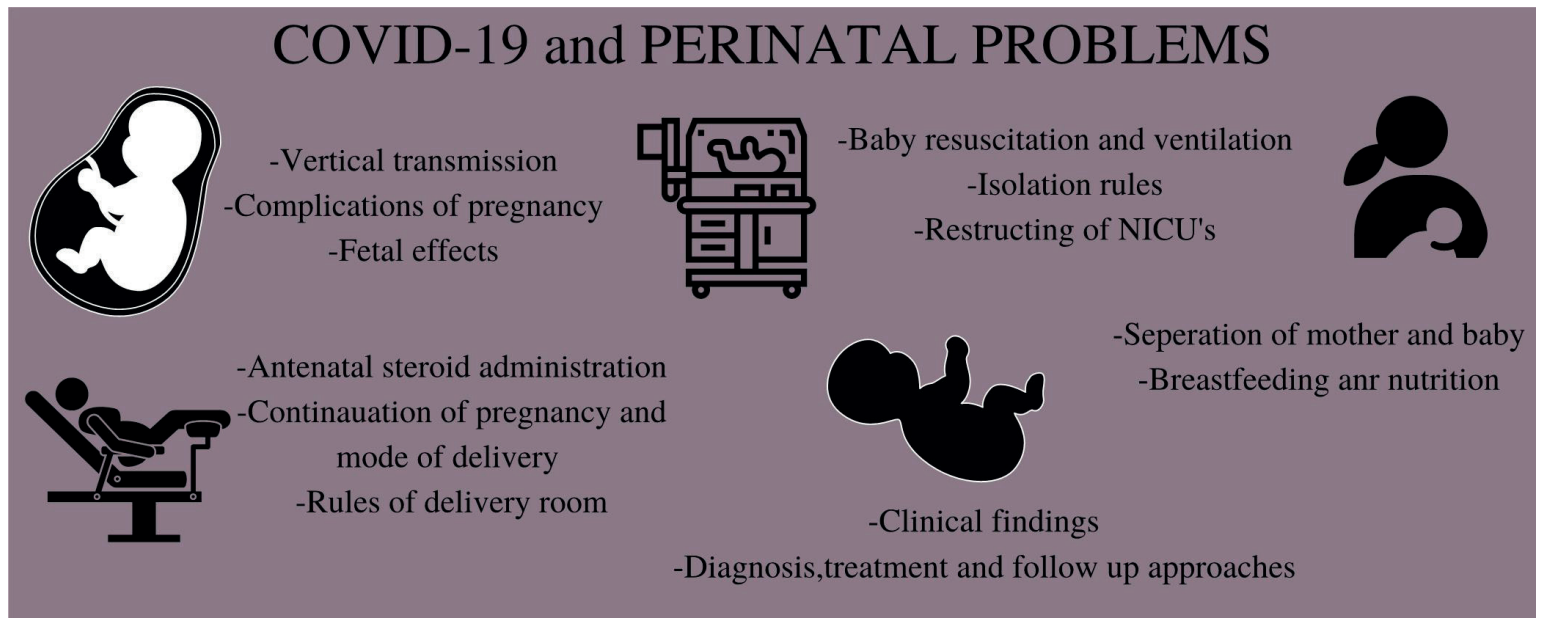

Fig. 1. COVID-19 and perinatal issues.

recommendations in the articles, reviews, guidelines, case series and case reports are presented.

\section{Fetal Effects and Vertical Transmission}

The course of the disease in pregnant women and the route of transmission are important in determining the management of newborn infants. In pregnant women infected with COVID-19, the need for intensive care, mechanical ventilation and mortality are significantly increased compared to nonpregnant infected women. ${ }^{6,7}$

The risk of vertical transmission and fetalneonatal effects may differ in each stage of pregnancy. Therefore, the physiology of the placenta and the pathological evaluation of the placental samples from pregnant women positive for COVID-19 are important in understanding the effects of the virus. Amniotic fluid, placenta, cord blood during delivery and respiratory tract samples of the baby should be carefully examined in terms of viral involvement in search of intrauterine transmission mechanisms.

Theoretically, four mechanisms related to intrauterine infection are possible. These mechanisms include; 1) Direct infection of syncytiotrophoblasts with the virus propagating through the syncytial layers via the angiotensin converting enzyme $\left(\mathrm{ACE}_{2}\right)$ and $\mathrm{Fc}$ receptor $(F c R), 2)$ Passage of the virus from the maternal circulation to extravillous trophoblasts or other placental cells, 3) Via maternal immune cells, 4) Vaginal infection and ascending route. ${ }^{8}$

COVID-19 binds to cells by $\mathrm{ACE}_{2}$ receptors and fuses into the cell with type II transmembrane serine protease (TTSP2). Placental $\mathrm{ACE}_{2}$ receptor expression and TTSP2 expressions have been reported to be low in the first two trimesters in fetal-placental tissues and both of them increase over time. ${ }^{9}$ In addition, it has been shown that the number of $\mathrm{ACE}_{2}$ receptors is higher in the endothelium of the umbilical artery in the placenta of preeclamptic pregnant women compared to those without preeclampsia. It is hypothesized that the risk of vertical transmission increases in COVID-19 positive pregnant women accompanied by preeclampsia. ${ }^{8}$ Thus, the maternal diseases and the physiology of the placenta in different periods of pregnancy are important in terms of vertical transmission.

It has been reported that thrombosis, fibrin deposits, villous stromal karyorrhexis and vascular perfusion disorders were the most common findings in the pathological examination of the placental samples..$^{8,10}$ 
At the beginning of the pandemic newborn babies of mothers who had COVID-19 infection in the third trimester were evaluated by upper respiratory tract real-time polymerase chain reaction (RT-PCR), amniotic fluid, blood PCR and blood IgM levels but there was no conclusive evidence of vertical transmission and no fetal or neonatal deaths were reported..$^{11-14}$

More recently, in a case report from India, a pregnant woman was found to be positive for coronavirus at the 8th gestational week. Hydrops fetalis and fetal loss occurred at the 13th week of gestation when the mother tested negative for the COVID-19 virus. Coronavirus genes were detected in the placenta, amniotic fluid and fetal membrane samples. Hydrops fetalis and fetal death were associated with COVID-19 infection in the first trimester as the other etiological factors were ruled out. The authors speculated on the persistence of the coronavirus replication in the placenta even after the mother tested negative in respiratory samples. ${ }^{15}$

In a multicenter study COVID-19-related fetal and neonatal outcomes were evaluated. Fetal and neonatal deaths were mostly associated with prematurity and correlated with the severity of the mother's clinical condition. However, conclusive evidence of vertical transmission could not be demonstrated. ${ }^{16}$
Vertical transmission is still an important question to be answered. Although various mechanisms have been proposed, there is a need for high quality evidence to show intrauterine transmission of COVID-19 (Fig. 2).

\section{Antenatal Corticosteroids}

Antenatal steroids (ANS) increase lung maturation by stimulating type 2 alveolar cell development in the fetus. $\mathrm{ACE}_{2}$ receptors are also found in these cells. Thus, it is thought that the administration of ANS may be harmful to the fetus by stimulating $\mathrm{ACE}_{2}$ receptor expression. However, as the maturation of these receptors occurs in late childhood or even during adolescence. ${ }^{17}$ Considering the short and long term benefits of ANS in preterm babies, it is recommend to be administered to COVID-19 infected pregnant women with preterm birth risk. ${ }^{18}$ However the effects of steroid administration to mothers infected with COVID-19 are not yet clear, The American College of Obstetricians and Gynecologists (ACOG) recommends the administration of betamethasone $(2 \times 12 \mathrm{mg})$ to pregnant women with either asymptomatic COVID-19 infection or with mild symptoms ${ }^{7}$ In pregnant women with severe coronavirus related disease, it is recommended to make a decision together with the family by informing them about the beneficial effects on the baby and the complications that may occur in the mother., 78

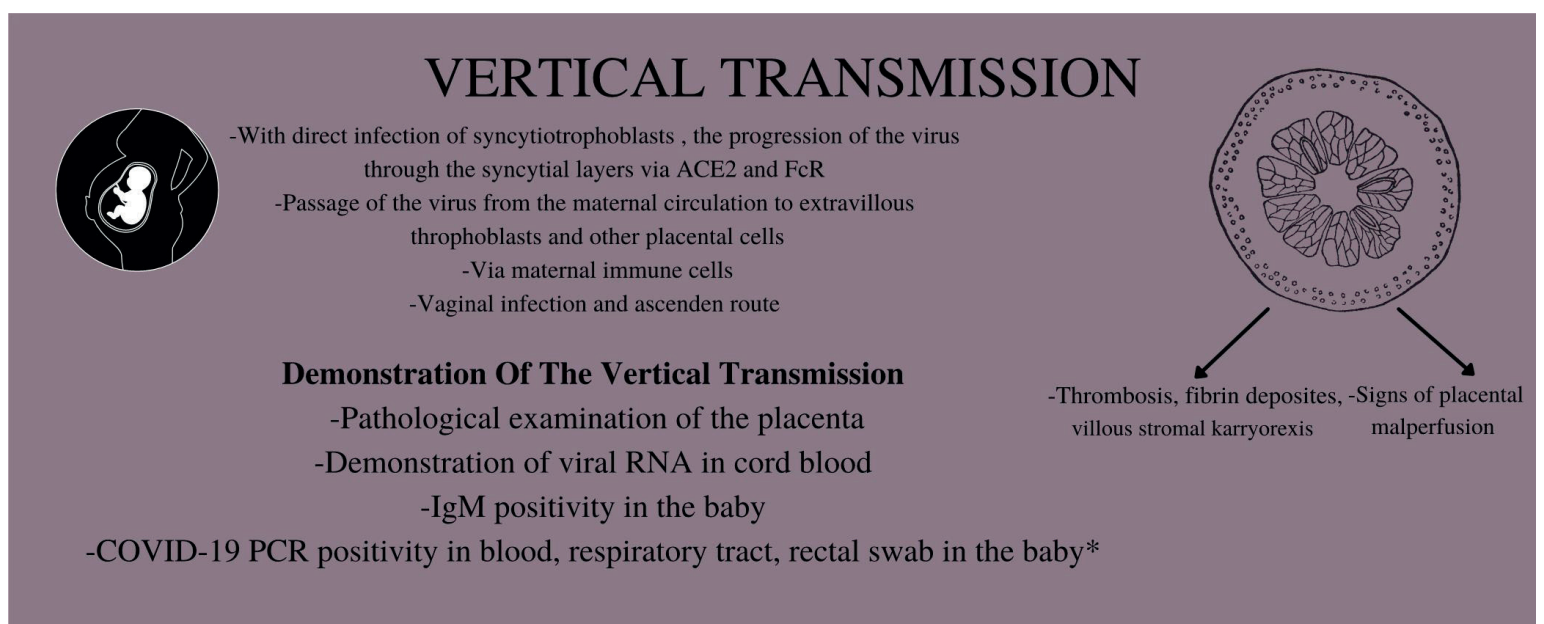

Fig. 2. COVID-19 and possible vertical tranmission mechanisms. 


\section{Delivery Room Management and Resuscitation}

The timing and delivery method of COVID-19 positive pregnant women should be determined according to obstetric indications as the delivery method has no effect on neonatal infection. ${ }^{7,19-22}$

Pregnant women with suspected or proven COVID-19 infection should be taken to a room with negative pressure. Since the use of general anesthesia during emergency cesarean section increases the risk of aerosol transmission, the delivery team should use personal protective equipment (PPE) (protective apron, N95 mask, visor, mask, gloves). All pregnant women with a diagnosis of or suspected COVID-19 infection should wear a surgical mask during delivery. The baby may be taken to a different room preferably. If this is not possible post delivery care should be given in an area separated by a physical barrier 2 meters away from the mother. ${ }^{718}$ After the first evaluation, if there is no need for resuscitation, the baby should be transferred to the neonatal intensive care unit (NICU) with a transport incubator. ${ }^{18,23}$ If the newborn baby needs resuscitation, Neonatal Resuscitation Program guidelines should be followed. ${ }^{18,24}$ Aeresole generating procedures like aspiration, balloon-mask ventilation, T-piece resuscitator use and intubation may be needed during resuscitation. Therefore, appropriate measures should be taken to prevent transmission of infection. ${ }^{7,22}$

There were controversial opinions about delayed cord clamping (DCC) and skin to skin contact after birth at the beginning of the pandemic. Updated recommendations by $\mathrm{WHO}$ is to follow usual the guidelines and maintain DCC and skin to skin contact in COVID-19 infected mothers after birth. ${ }^{25}$

\section{Postnatal Care and Follow Up of Newborn Infants}

Since there was no clear information about the course of the disease in newborn babies in the first months of the pandemic, it was recommended that the baby born to mothers with suspected or confirmed COVID-19, should be isolated and followed in the NICU. ${ }^{19}$ In the later stages of the pandemic, this recommendation changed to keep the mother and the baby in the same room with a minimum number of people if the baby has no postnatal adaptation problems..$^{26,27}$

Bathing the baby immediately after birth is no longer recommended as there are no proven benefits and the risk of hypothermia is high. ${ }^{28}$

All newborn infants born to mothers with suspected or confirmed COVID-19 infection should be tested for COVID-19 RNA with RT-PCR in the upper respiratory tract and nasopharyngeal samples twice at 24 and 48 hours after birth or once at 24 or 48 hours of age. ${ }^{29}$ If there is any doubt of intrauterine or postnatal infection of COVID-19, additional samples from sterile sites such as blood, lower respiratory tract and cerebrospinal fluid should also be tested by PCR. ${ }^{30}$

Asymptomatic babies can be discharged home with a close follow up programme. ${ }^{29}$

\section{Clinical Findings and Treatment in COVID-19 Infected Neonates}

\section{Symptoms and Laboratory Evaluation}

There are no specific clinical findings in neonates as with other cases of sepsis. Nonspecific findings like feeding intolerance, vomiting, tachypnea, respiratory distress, tachycardia, circulatory disorders make it difficult to recognize COVID-19 infection in newborns. ${ }^{31}$ In a case series including 44 COVID-19 positive neonates reported as fever $(50 \%)$, gastrointestinal symptoms $(26 \%)$, hypoxia $(20 \%)$ and cough $(20 \%)$ were the most common symptoms. ${ }^{32}$

Laboratory findings of COVID-19 infection in neonates are also non-specific and include leukocytosis, lymphopenia, thrombocytopenia, elevated inflammatory markers and non-specific radiologic markers on chest radiography. ${ }^{20}$ 
Contrary to what was reported in the early days of the pandemic, it is now known that the disease can progress to serious neonatal pneumonia and multiple organ failure in newborn infants. Inflammatory clinical conditions with multisystem involvement due to COVID-19 have also been encountered in newborn babies similar to Multisystem inflammatory syndrome in children (MIS-C). This condition caused by the hyperinflammatory response in newborn babies has been defined as Neonatal MIS-C (MIS-N). ${ }^{22}$

Infants with MIS-N have negative for PCR tests but test positive for COVID-19 immunoglobulin G. They may have cardiac involvement (myocarditis, increased Troponin $\mathrm{T}$ and brain natriuretic peptide levels), respiratory distress (pulmonary infiltrates, pulmonary hypertension), gastrointestinal symptoms (feeding intolerance, vomiting, necrotizing enterocolitis like findings), hematological findings (disseminated intravascular coagulopathy, thrombocytopenia, lymphopenia, neutropenia) and renal failure. In MIS-N cases, it has been reported that intravenous immunoglobulin and steroids are used together with other supportive treatments. $22,33-35$

\section{Medical Treatment}

There is no evidence based recommendations other than supportive treatment, especially in asymptomatic cases in the neonatal period. To our knowledge, there is insufficient data on the neonatal use of antiviral agents used in adults like lopinavir, ritonavir and remdesevir. However, there are reports on the use of remdesevir, intravenous immunoglobulin, steroids and even monoclonal antibodies in severe clinical conditions such as sepsis, severe respiratory failure and multi-inflammatory response syndrome. ${ }^{36-38}$

\section{Respiratory Support}

Mechanical ventilation, surfactant therapy, inhaled nitric oxide and even extracorporeal membrane oxygenation may be needed in severe cases. ${ }^{19}$ The number of newborn babies receiving respiratory support due to COVID-19 is low. It is recommended to use a HEPA filter with bagmask ventilation, to wear a PPE during care and intervention, to use a video laryngoscope during intubation. ${ }^{22}$ It is known that the use of a closed suction system in intubated patients reduces the transmission through droplets. ${ }^{18}$ Although adult guidelines recommend clamping the tube during intubation and extubation to minimize the risk of contamination, there are limited data for newborns. ${ }^{39}$

\section{Breastfeeding and Nutrition}

In mothers who are positive for SARS-CoV2, both droplet transmission and transmission through breast milk are possible risks. However, there is currently no conclusive evidence of COVID-19 transmission through breast milk. Therefore, appropriate hygiene measures should be taken and breastfeeding should be continued considering the benefits for both the mother and the baby. ${ }^{40}$

In the last publication from WHO on breastfeeding and COVID-19, it was stated that the most appropriate approach for the mother is to continue breastfeading with careful hand washing and wearing a mask. If the general condition of the mother is not suitable for breastfeeding, it is emphasized that the baby can still be fed with pumped breast milk. In cases where own mother's milk is not available donor milk or formula milk can be used. It is important to continue breastfeeding counseling should be repeated after the mother's health status improves (Fig. 3). ${ }^{41}$

In the multicenter retrospective study of the Turkish Neonatal Society, it was reported that breastfeeding rates in babies of COVID-19 positive mothers were low (36\%). This situation was explained by the isolation of the babies in the NICU, the clinical status of the mothers, the concerns of the family and healthcare workers about the possibility of transmission of the virus by breast milk. ${ }^{42}$ 


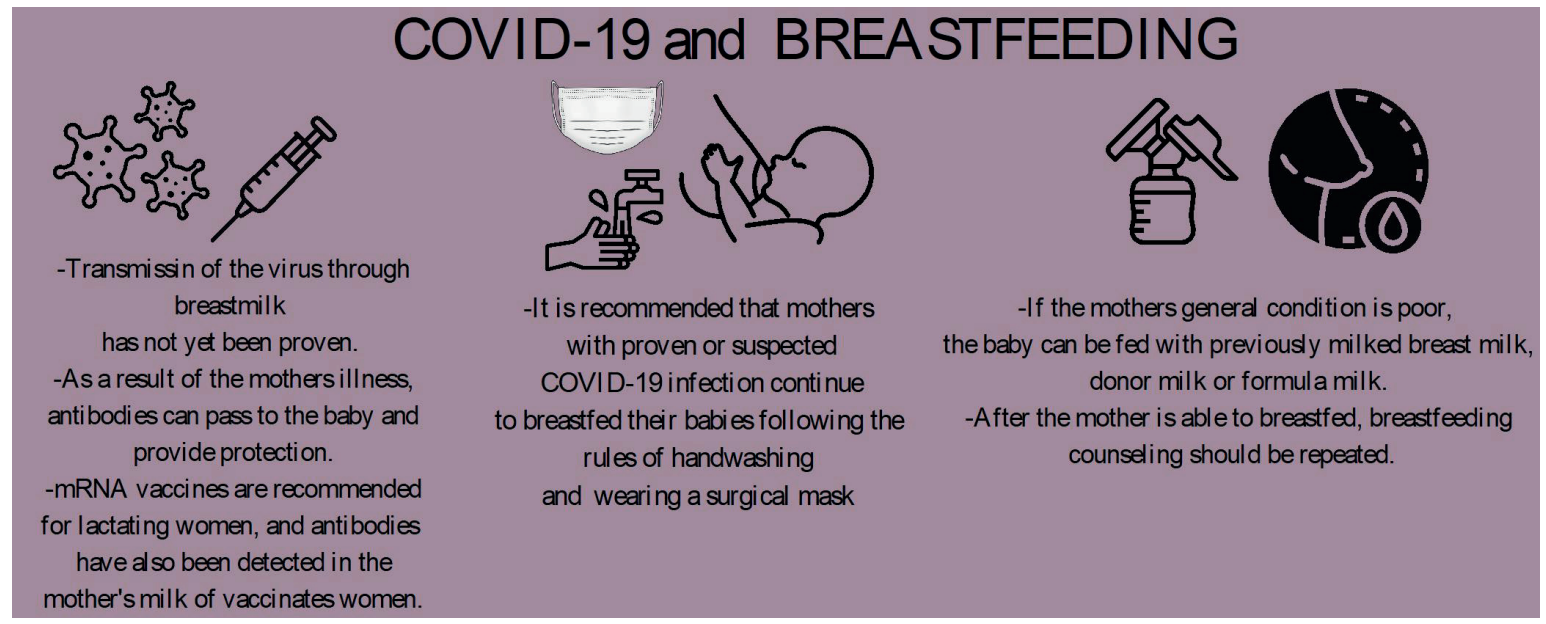

Fig. 3. COVID-19 and breastfeeding.

There is insufficient data about the effects of antiviral drugs in lactating mothers in breastfed babies. Commonly used RNA polymerase inhibitors in the treatment of COVID-19 are favipiravir and remdesevir. Remdesevir has been used in the treatment of Ebola virus infection in newborns and also in babies who developed serious illness during the COVID-19 infection in selected cases. Therefore, it has been stated that remdesevir can be used with caution in breastfeeding women, with close monitoring of side effects in the neonates. ${ }^{43-45}$

Favipiravir is another antiviral agent frequently used in the treatment of COVID-19. Teratogenic effects during pregnancy have been shown but we have insufficient information on the transition to breast milk and its effects on newborns. Based on animal studies, there are publications stating that it is contraindicated during breastfeeding. The Turkish Ministry of Health does not recommend the use of favipiravir either during pregnancy or lactating women. ${ }^{43-46}$

\section{Vaccination in Pregnancy and Lactating Women}

The rapid spread of COVID-19 and increasing mortality have caused a number of vaccines to receive emergency approval for use. However pregnant and lactating women were excluded from the COVID-19 vaccine studies which makes it difficult to recommend their use in this population..$^{47,48}$

In a recent study comparing the immune response to two mRNA (Pfizer-BioNTech and Moderna) vaccines in pregnant, lactating and non-pregnant women, the immunogenic response was found to be equivalent in all three groups. Specific IgG was detected in the cord blood of the newborn babies and breast milk of these mothers showing immune transfer via the placenta and breast milk. ${ }^{49}$

In another very recent study data of 35691 pregnant women vaccinated with two mRNA COVID-19 vaccines were collected. The most common side effects were local pain at the injection site, vomiting and headache. There were 827 completed pregnancies out of which $115(13.9 \%)$ resulted in pregnancy loss and 712 $(86.1 \%)$ resulted in live birth. The incidence of prematurity was reported as $9.4 \%$ and small for gestational age as $3.2 \%$. Prematurity was found to be higher when compared to pregnant women who were not vaccinated, and no significant difference was found in other pregnancy outcomes. Neonatal death has not been reported..$^{50}$ 
To prevent COVID-19 infection in newborn infants' the vaccination of the mothers is an important issue although the available data is not sufficient to either support or refuse the use of vaccines in pregnancy. Future studies evaluating the effects of vaccine administration during pregnancy and lactating women are needed to make evidence based recommendations in this population of women.

The weak immune systems of newborn babies have been a source of concern in neonatology during the COVID-19 pandemic. Both insufficient data on the effects of the virus and the low number of patients have created limitations in the development of follow-up and treatment approaches.

Our knowledge of the perinatal and neonatal effects of COVID-19 infection changes rapidly. Therefore, close follow-up of the mother-infant dyads is important. Larger epidemiological and clinical cohort studies are needed to better understand the possible implications and the long-term outcomes of the COVID-19 infection and also maternal vaccination in newborn infants.

Also, long-term follow-up of babies of mothers who had COVID-19 infection during pregnancy and newborns infected with COVID-19 gains importance.

\section{Author contribution}

The authors confirm contribution to the paper as follows: study conception and design: LKB, DT; data collection: LKB, AÇ, DT; analysis and interpretation of results: ZI, DT; draft manuscript preparation: Zİ, AÇ. All authors reviewed the results and approved the final version of the manuscript.

\section{Conflict of interest}

The authors declare that there is no conflict of interest.

\section{REFERENCES}

1. Abduljalil JM, Abduljalil BM. Epidemiology, genome, and clinical features of the pandemic SARS-CoV-2: a recent view. New Microbes New Infect 2020; 35: 100672. https://doi.org/10.1016/j. nmni.2020.100672

2. Çokuğraş $\mathrm{H}$, Önal P. SARS-CoV-2 infection in children. Turk Pediatri Ars 2020; 55: 95-102. https:// doi.org/10.14744/TurkPediatriArs.2020.20270

3. World Health Organization. Coronavirus disease 2019 (COVID-19) Situation Report-74. Available at: https://www.who.int/docs/default-source/ coronaviruse/situation-reports/20200403-sitrep-74covid-19-mp.pdf

4. Bi Q, Wu Y, Mei S, et al. Epidemiology and transmission of COVID-19 in 391 cases and 1286 of their close contacts in Shenzhen, China: a retrospective cohort study. Lancet Infect Dis 2020; 20: 911-919. https://doi.org/10.1016/S14733099(20)30287-5

5. Zimmermann $\mathrm{P}$, Curtis N. Coronavirus infections in children including COVID-19: an overview of the epidemiology, clinical features, diagnosis, treatment and prevention options in children. Pediatr Infect Dis J 2020; 39: 355-368. https://doi.org/10.1097/ INF.0000000000002660

6. Zambrano LD, Ellington S, Strid P, et al. Update: characteristics of symptomatic women of reproductive age with laboratory-confirmed SARSCoV-2 infection by pregnancy status - United States, January 22-October 3, 2020. MMWR Morb Mortal Wkly Rep 2020; 69: 1641-1647. https://doi. org/10.15585/mmwr.mm6944e3

7. American College of Obstetricians and Gynecologists. COVID-19 FAQs for obstetriciangynecologists, obstetrics. Available at: https:// www.acog.org/clinical-information/physician-faqs/ covid19-faqs-for-ob-gyns-obstetrics (Accessed on January 27, 2021).

8. Komine-Aizawa S, Takada K, Hayakawa S. Placental barrier against COVID-19. Placenta 2020; 99: 45-49. https://doi.org/10.1016/j.placenta.2020.07.022

9. Li M, Chen L, Zhang J, Xiong C, Li X. The SARSCoV-2 receptor ACE2 expression of maternalfetal interface and fetal organs by single-cell transcriptome study. PLoS One 2020; 15: e0230295. https://doi.org/10.1371/journal.pone.0230295

10. Mulvey JJ, Magro CM, Ma LX, Nuovo GJ, Baergen RN. Analysis of complement deposition and viral RNA in placentas of COVID-19 patients. Ann Diagn Pathol 2020; 46: 151530. https://doi.org/10.1016/j. anndiagpath.2020.151530 
11. Schwartz DA. An analysis of 38 pregnant women with COVID-19, their newborn infants, and maternal-fetal transmission of SARS-CoV-2: maternal coronavirus infections and pregnancy outcomes. Arch Pathol Lab Med 2020; 144: 799-805. https://doi.org/10.5858/arpa.2020-0901-SA

12. Zeng $\mathrm{H}, \mathrm{Xu} \mathrm{C}$, Fan J, et al. Antibodies in infants born to mothers with COVID-19 pneumonia. JAMA 2020; 323: 1848-1849. https://doi.org/10.1001/ jama.2020.4861

13. Sheth S, Shah N, Bhandari V. Outcomes in COVID-19 positive neonates and possibility of viral vertical transmission: a narrative review. Am J Perinatol 2020; 37: 1208-1216. https://doi.org/10.1055/s-0040-1714719

14. Breslin N, Baptiste C, Gyamfi-Bannerman C, et al. Coronavirus disease 2019 infection among asymptomatic and symptomatic pregnant women: two weeks of confirmed presentations to an affiliated pair of New York City hospitals. Am J Obstet Gynecol MFM 2020; 2: 100118. https://doi. org/10.1016/j.ajogmf.2020.100118

15. Shende P, Gaikwad P, Gandhewar M, et al. Persistence of SARS-CoV-2 in the first trimester placenta leading to transplacental transmission and fetal demise from an asymptomatic mother. Hum Reprod 2021; 36: 899-906. https://doi.org/10.1093/ humrep/deaa367

16. WAPM (World Association of Perinatal Medicine) Working Group on COVID-19. Maternal and perinatal outcomes of pregnant women with SARSCoV-2 infection. Ultrasound Obstet Gynecol 2021; 57: 232-241. https://doi.org/10.1002/uog.23107

17. Muus C, Luecken MD, Eraslan G, et al. Integrated analyses of single-cell atlases reveal age, gender, and smoking status associations with cell type-specific expression of mediators of SARS-CoV-2 viral entry and highlights inflammatory programs in putative target cells. BioRxiv 049254 [Preprint]. https://doi. org/10.1101/2020.04.19.049254

18. Chandrasekharan P, Vento M, Trevisanuto D, et al. Neonatal resuscitation and postresuscitation care of infants born to mothers with suspected or confirmed SARS-CoV-2 infection. Am J Perinatol 2020; 37: 813824. https://doi.org/10.1055/s-0040-1709688

19. World Health Organization. Clinical management of severe acute respiratory infection (SARI) when COVID-19 disease is suspected interim guidance. Pediatr Med Rodz 2020; 16: 9-26. https://doi. org/10.15557/PiMR.2020.0003

20. Wang L, Shi Y, Xiao T, et al. Chinese expert consensus on the perinatal and neonatal management for the prevention and control of the 2019 novel coronavirus infection (First edition). Ann Transl Med 2020; 8: 47. https://doi.org/10.21037/atm.2020.02.20
21. Walker KF, O'Donoghue K, Grace N, et al. Maternal transmission of SARS-COV-2 to the neonate, and possible routes for such transmission: a systematic review and critical analysis. BJOG 2020; 127: 13241336. https://doi.org/10.1111/1471-0528.16362

22. Sankaran D, Nakra N, Cheema R, Blumberg D, Lakshminrusimha S. Perinatal SARS-CoV-2 infection and neonatal COVID-19: a 2021 update. Neoreviews 2021; 22: e284-e295. https://doi.org/10.1542/neo.225-e284

23. Vogel JP, Tendal B, Giles M, et al. Clinical care of pregnant and postpartum women with COVID-19: living recommendations from the National COVID-19 Clinical Evidence Taskforce. Aust N Z J Obstet Gynaecol 2020; 60: 840-851. https://doi. org/10.1111/ajo.13270

24. Puopolo KM, Hudak ML, Kimberlin DW, Cummings $\mathrm{J}$, American Academy of Pediatrics Committee on Fetus and Newborn Section of Neonatal Perinatal Medicine and Committee on Infectious Disease. Initial guidance: management of infants born to mothers with COVID-19. Available at: https:// www.tn.gov/content/dam/tn/health/documents/ cedep/novel-coronavirus/AAP_COVID-19-InitialNewborn-Guidance.pdf (Accessed on April 2, 2020).

25. World Health Organization. Clinical management of COVID-19. Available at: https://www.who.int/ publications/i/item/clinicalmanagement-of-covid-19 (Accessed on January 27, 2021).

26. Barrero-Castillero A, Beam KS, Bernardini LB, et al. COVID-19: neonatal-perinatal perspectives. J Perinatol 2021; 41: 940-950. https://doi.org/10.1038/ s41372-020-00874-x

27. Amatya S, Corr TE, Gandhi CK, et al. Management of newborns exposed to mothers with confirmed or suspected COVID-19. J Perinatol 2020; 40: 987-996. https://doi.org/10.1038/s41372-020-0695-0

28. Vardhelli V, Pandita A, Pillai A, Badatya SK. Perinatal COVID-19: review of current evidence and practical approach towards prevention and management. Eur J Pediatr 2021; 180: 1009-1031. https://doi.org/10.1007/s00431-020-03866-3

29. Centers for Disease Control and Prevention. Evaluation and management considerations for neonates at risk for COVID-19. Available at: https:// www.cdc.gov/coronavirus/2019-ncov/hcp/ caringfor-newborns.html (Accessed on January 27, 2021).

30. World Health Organization. Definition and categorization of the timing of mother-to-child transmission of SARS-CoV-2. February, 2021. Available at: https://www.who.int/publications/i/ item/WHO-2019-nCoV-mother-to-childtransmission-2021.1 
31. Kanburoglu MK, Tayman C, Oncel MY, et al. A multicentered study on epidemiologic and clinical characteristics of 37 neonates with community-acquired COVID-19. Pediatr Infect Dis J 2020; 39: e297-e302. https://doi.org/10.1097/ INF.0000000000002862

32. Trevisanuto D, Cavallin F, Cavicchiolo ME, Borellini M, Calgaro S, Baraldi E. Coronavirus infection in neonates: a systematic review. Arch Dis Child Fetal Neonatal Ed 2021; 106: 330-335. https://doi. org/10.1136/archdischild-2020-319837

33. Khaund Borkotoky R, Banerjee Barua P, Paul SP, Heaton PA. COVID-19-Related potential multisystem inflammatory syndrome in childhood in a neonate presenting as persistent pulmonary hypertension of the newborn. Pediatr Infect Dis J 2021; 40: e162-e164. https://doi.org/10.1097/ INF.0000000000003054

34. Kappanayil M, Balan S, Alawani S, et al. Multisystem inflammatory syndrome in a neonate, temporally associated with prenatal exposure to SARS-CoV-2: a case report. Lancet Child Adolesc Health 2021; 5: 304308. https://doi.org/10.1016/S2352-4642(21)00055-9

35. Farias ECF, Justino MCA, Mello MLFMF. Multisystem inflammatory syndrome in a child associated with coronavirus disease 19 in the Brazilian amazon: fatal outcome in an infant. Rev Paul Pediatr. 2020; 38: e2020165. https://doi. org/10.1590/1984-0462/2020/38/2020165

36. Trieu C, Poole C, Cron RQ, et al. Severe neonatal coronavirus disease 2019 presenting as acute respiratory distress syndrome. Pediatr Infect Dis J 2020; 39: e367-e369. https://doi.org/10.1097/ INF.0000000000002864

37. Cook J, Harman K, Zoica B, Verma A, D'Silva P, Gupta A. Horizontal transmission of severe acute respiratory syndrome coronavirus 2 to a premature infant: multiple organ injury and association with markers of inflammation. Lancet Child Adolesc Health 2020; 4: 548-551. https://doi.org/10.1016/ S2352-4642(20)30166-8

38. Saikia B, Tang J, Robinson S, et al. Neonates with SARS-CoV-2 infection and pulmonary disease safely treated with remdesivir. Pediatr Infect Dis J 2021; 40: e194-e196. https://doi.org/10.1097/ INF.0000000000003081

39. Kovacs G, Sowers N, Campbell S, French J, Atkinson P. Just the facts: airway management during the coronavirus disease 2019 (COVID-19) pandemic. CJEM 2020; 22: 440-444. https://doi.org/10.1017/ cem.2020.353

40. Lubbe W, Botha E, Niela-Vilen H, Reimers P. Breastfeeding during the COVID-19 pandemic - a literature review for clinical practice. Int Breastfeed J 2020; 15: 82. https://doi.org/10.1186/s13006-02000319-3
41. World Health Organization. Breastfeeding and COVID-19 for health care workers. 2020. Available at: https://cdn.who.int/media/docs/default-source/ maternal-health/faqs-breastfeeding-and-covid19_805d4ce8-2329-4227-9261-695afa68b32c.pdf

42. Oncel MY, Akın IM, Kanburoglu MK, et al. A multicenter study on epidemiological and clinical characteristics of 125 newborns born to women infected with COVID-19 by Turkish Neonatal Society. Eur J Pediatr 2021; 180: 733-742. https://doi. org/10.1007/s00431-020-03767-5

43. Anderson PO. Antivirals for COVID-19 and breastfeeding. Breastfeed Med 2020; 15: 605-607. https://doi.org/10.1089/bfm.2020.0268

44. Cavalcante MB, Cavalcante CTMB, Braga ACS, et al. COVID-19 treatment: drug safety prior to conception and during pregnancy and breastfeeding. Geburtshilfe Frauenheilkd 2021; 81: 46-60. https:// doi.org/10.1055/a-1247-5271

45. Naseri A, Seyedi Sahebari S, Hosseini MS. Pharmacotherapy of COVID-19: considerations for pregnancy and breastfeeding. Preprints 2021, 2021050311. https://doi.org/10.20944/ preprints202105.0311.v1

46. T.C. Sağlık Bakanlığı. Covid-19 (SARS-CoV-2 Enfeksiyonu) Solunum Sistemi Hastalıklarının Yaygın Olduğu Dönemde Sağlık Kuruluşlarında Gebe Takibi. Avaliable at: https://covid19.saglik.gov. tr/Eklenti/41676/0/Covid-19solunumsistemihastalikl arininyayginoldugudonemdesaglikkuruluslarindag ebetakibipdf.pdf (Accessed on Oct 11, 2021)

47. Blumberg D, Sridhar A, Lakshminrusimha S, Higgins RD, Saade G. COVID-19 vaccine considerations during pregnancy and lactation. Am J Perinatol 2021; 38: 523-528. https://doi.org/10.1055/s-0041-1726390

48. Food and Drug Administration. Vaccines and related biological products advisory committee meeting: FDA briefing document Moderna COVID-19 vaccine. Available at: https://www.fda. gov/media/144434/download (Accessed on January 27, 2021).

49. Gray KJ, Bordt EA, Atyeo C, et al. COVID-19 vaccine response in pregnant and lactating women: a cohort study. medRxiv 21253094 [Preprint]. https://doi. org/10.1101/2021.03.07.21253094

50. Shimabukuro TT, Kim SY, Myers TR, et al. Preliminary findings of mRNA Covid-19 vaccine safety in pregnant persons. N Engl J Med 2021; 384: 2273-2282. https://doi.org/10.1056/NEJMoa2104983 